\title{
Medical Image of the Week: Coronary Artery Ectasia
}

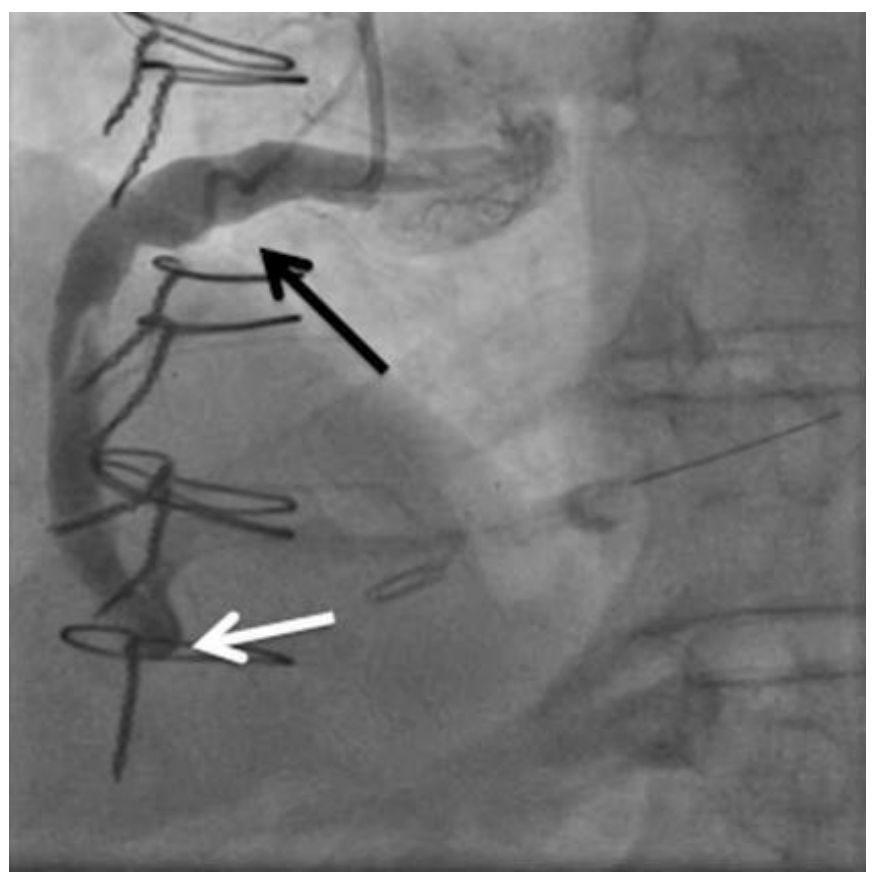

Figure 1. Coronary angiogram demonstrating ectatic right coronary artery (black arrow) with minimal laminar flow of contrast dye. $100 \%$ occlusion of distal RCA noted (white arrow), as well as sternotomy wires from prior CABG.

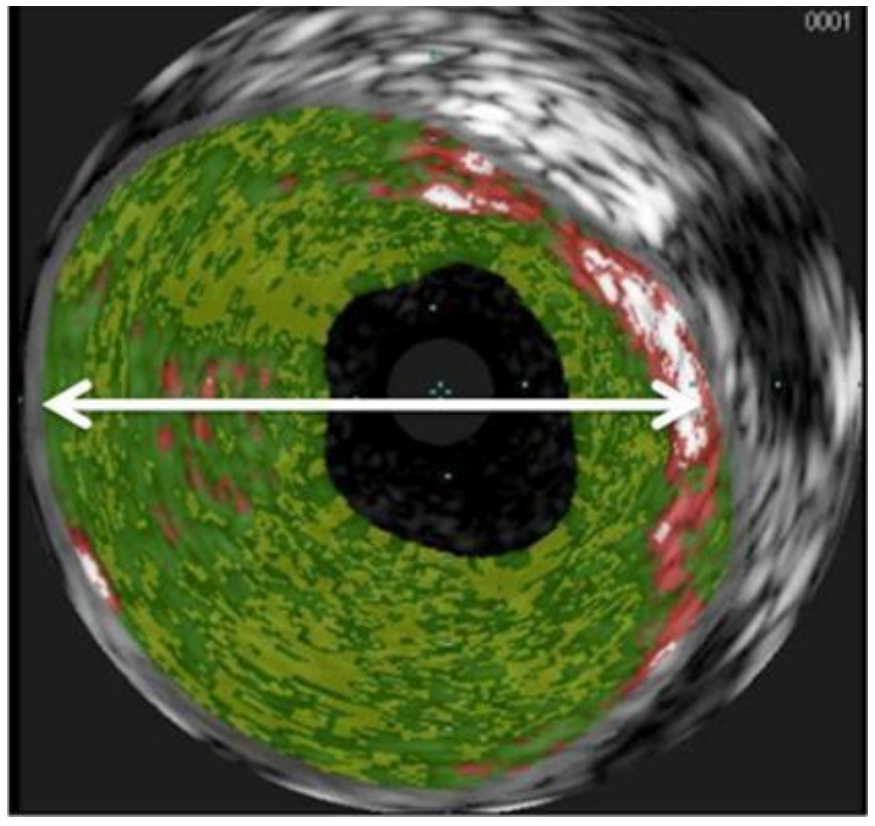

Figure 2. Intravascular ultrasound (IVUS) demonstrating dilated, ectatic right coronary artery with maximum dimension 9-10 $\mathrm{mm}$ (white line). 
A 70-year-old man with a history of coronary artery disease and previous 3 vessel coronary artery bypass grafting (CABG) was admitted to the coronary care unit with acute chest pain and EKG concerning for ST elevations in II, III, aVF with first degree AV block. Troponins were negative on admission, and peaked at $35 \mathrm{ng} / \mathrm{ml}$. The patient was taken immediately to the cardiac catherization lab for acute inferior ST elevation myocardial infarction (STEMI), and was found to have coronary artery ectasia throughout with diffuse atherosclerotic disease. $100 \%$ occlusion was noted in the distal RCA, but the wire was not able to be passed through the blockage due to tortuous and dilated vessels vessels. Left circumflex and left anterior descending arteries showing similar ectatic findings without acute blockage. No stents were able to be engaged in the RCA given the large diameter from the ectasia. The RCA notably had a diameter of 7-10 mm in width with minimal laminar flow of contrast dye (Figure1), and was confirmed with Intravascular Ultrasound (IVUS, Figure 2). Echocardiogram showed an ejection fraction of $55 \%$ with normal left ventricular function. Since stents were not able to be placed, the patient was medically optimized with aspirin, ticagrelor, and a high intensity statin. The patient felt improved following medical optimization, and was discharged home in stable condition with cardiology follow up.

Coronary ectasia is a disease of the coronary arteries in which the vessel lumen is increased greater than 1.5 times in size (1). It is a very rare finding, with only $1.2-2 \%$ of coronary caths demonstrating ectasia. Clinical findings are believed to be due to increased wall stress and thinning of the arterial wall in the setting of atherosclerosis causing progressive dilation and remodeling (2). Ectasia is also commonly found in patients with connective tissue disease and vasculitis, classically Marfan syndrome and Kawasaki disease. Conventional stents are generally too small in diameter to be utilized. Treatment is largely devoted towards decreasing cardiac risk factors and avoiding medications that slow coronary blood flow such as nitrates (3).

Adam Berlinberg MD1, Steven Stroud MD1, Jaren Trost MD¹, Karl Kern MD² ${ }^{1}$ Department of Internal Medicine and ${ }^{2}$ Department of Cardiology, Sarver Heart Center, Banner University Medical Center; Tucson, AZ

\section{References}

1. Lin CT, Chen CW, Lin TK, Lin CL. Coronary artery ectasia. Tzu Chi Med J 2008;20:270-4. [CrossRef]

2. Hsu PC, Su HM, Lee HC, Juo SH, Lin TH, Voon WC, Lai WT, Sheu SH. Coronary artery collateral circulation in patients of coronary ectasia with significant coronary artery disease. PLoS One. 2014;9(1): e87001. [CrossRef] [PubMed]

3. Eitan A, Roguin A. Coronary artery ectasia: new insights into pathophysiology, diagnosis, and treatment. Coron Artery Dis 2016;27(5):420-

8. [CrossRef] [PubMed] 